\title{
JOURNAL.RU
}

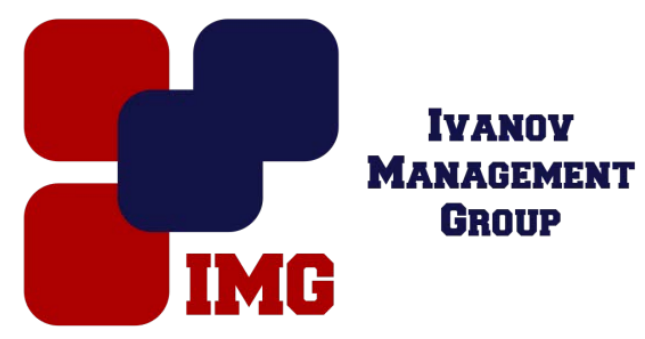

\author{
Лукьянова В. О., Мельников А. Г. \\ Саратовский государственный технический университет имени Гагарина Ю.А. \\ Саратов, Россия
}

doi: 10.18411/lj-31-01-2017-3-01

idsp 000001:lj-31-01-2017-3-01

\section{К вопросу о модернизации конструкции дерматоскопа на основе кросс-поляризации}

Научный руководитель: Пичхидзе С.Я.

С каждым годом растёт число заболеваемых раком кожи, возникает необходимость более тщательного обследования кожного покрова на ранних стадиях развития заболеваний. Для выявления очагов болезни используют кросс-поляризованный дерматоскоп. Существует несколько конструкций дерматоскопа, которые могут работать в режиме кросс-поляризации [1-3].

Цель настоящей работы: провести спектральный анализ заменителя кожи и представить модель дерматоскопа на основе кросс-поляризации.

Объекты и метод исследования: спектральный анализ был проведен на спектрофлуориметре образцах свиной кожи квадратной формы, размером $1 \times 1$ см2, поскольку она наиболее схожа по структуре с человеческой [4].

В результате эксперимента была определена собственная флуоресценция кожи с максимумом на длине волны 490 нм при возбуждении на длине волны 380 нм, рис.1а. При добавлении эозина на поверхность кожи наблюдалось уменьшение интенсивности собственной флуоресценции кожи приблизительно на 30\%, что может быть связано с взаимодействием эозина с флуорофорами, входящими в состав кожи, так как эозин на длине волны 380 нм практически не поглощает свет. Также была зарегистрирована флуоресценция эозина, связанного с кожей, с максимумом на 550 нм при возбуждении на длине волны 280 нм, рис.1б. Исходя из полученных результатов спектрального анализа свиной кожи была предложена следующая конструкция дерматоскопа, рис.1в. 


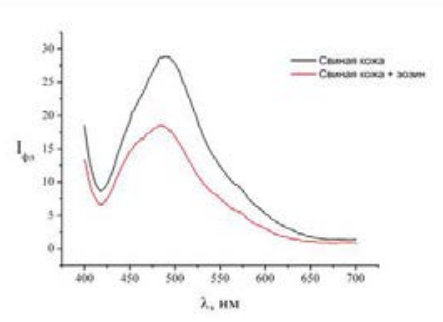

a)

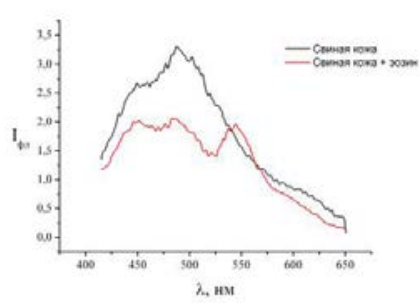

б)

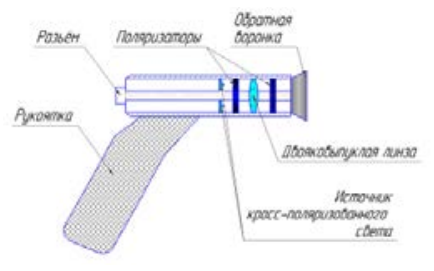

6)

Рис.1. Спектр испускания флуоресценџии свиной кожи с эозином на поверхности (красная линия) и без него (синяя линяя) при возбуждении на длинах волн 380 нм (а)и 280 нм (б); конструкция дерматоскопа на основе кросс-поляризации (в)

Предлагаемая конструкция дерматоскопа содержит светодиодную матрицу с поляризационными светодиодами, два поляризатора с разными направлениями поляризации, между ними располагается двояковыпуклая линза. В целом, благодаря выше описанной структуре происходит режим кросс-поляризации.

Выводы: в результате спектрального анализа определена флуоресценция кожи с эозином и без эозина. Для выявления связи наблюдаемого свечения с процессами переноса энергии или с непосредственным возбуждением эозина необходимы дальнейшие исследования. Предложенная в работе модель дерматоскопа позволяет осуществить исследование кожи в режиме кроссполяризации и упрощает использование аппарата за счет формы конструкции.

\section{Литература}

1. Systematic design of a cross-polarized dermoscope for visual inspection and digital imaging / Wang H. [et al.] //IEEE Instrumentation \& Measurement Magazine. - 2011. Vol. 14. - №. 6. - P. 26-31.

2. Лукьянова В. О. Разработка новой конструкции дерматоскопа на основе кроссполяризации // Тенденции развития науки и образования. Сборник научных трудов, по материалам XIX международной научно-практической конференции 31 октября 2016 г. Часть 1 Изд. НИЦ «Л-Журнал», 2016.// С. 17- 18.

3. Патент РФ на изобретение №2459572 от 17.03.2011. Дерматоскоп. Автор: Сергеев В.Ю. Опубл. 27.08.2012.

4. Buribayeva M., Irmuhametova G., Mun G. Development of hydrogel ointments with antituberculosis activity //Chemical Bulletin of Kazakh National University. - 2013. - №. 2. - C. $70-74$. 